\title{
ANALISIS KADAR SIKLAMAT DENGAN METODE KROMATOGRAFI CAIR KINERJA TINGGI PADA MINUMAN JAJANAN SEKOLAH DI KOTA PALU
}

\author{
An Analysis of Cycle Levels in School Snack Beverages in Palu City Using High \\ Performance Liquid Chromatography Method
}

\author{
Rusli Maudu ${ }^{1}$, Bahja ${ }^{2}$, Fahmi Hafid ${ }^{3}$, Dewi Susetiyany Ichsan ${ }^{4}$ \\ ${ }^{1,2,3}$ Poltekkes Kemenkes Palu \\ ${ }^{4}$ Balai Pengawasan Obat dan Makanan di Palu \\ (ruslimaudu63@gmail.com, 085242335590)
}

\begin{abstract}
ABSTRAK
Siklamat adalah pemanis buatan yang diproses secara kimiawi. Siklamat tidak boleh dipakai pada hasil pangan untuk bayi, anak batita, ibu hamil serta ibu menyusui. Batas maksimum penggunaan Siklamat adalah $0-11 \mathrm{mg} / \mathrm{kg}$ berat badan. Tujuan penelitian untuk mengetahui kadar siklamat pada minuman jajanan sekolah di Kota Palu, Penelitian ini menggunakan metode observasi di 8 (delapan) lokasi di Kota Palu pada tanggal 8-24 Agustus 2018. Analisis kadar Siklamat di Balai Pengawas Obat dan Makanan di Palu. Sampel sebanyak 20 minuman jajajan diperoleh dengan cara accidental sampling. Metode analisis dengan kromatografi cair kinerja tinggi (KCKT). Hasil penelitian menunjukkan bahwa kadar siklamat pada minuman jajanan sekolah di Kota Palu yang melebihi ambang batas perka BPOM $<350 \mathrm{mg} / \mathrm{Kg}$ sebanyak 35\% dengan kadar 514,63 hingg 2963,43 mg/Kg. Disarankan agar melakukan penelitan lebih lanjut tentang pengetahuan, sikap dan perilaku penjaja minuman dilokasi yang melebihi ambang batas perka BPOM $<350 \mathrm{mg} / \mathrm{Kg}$ serta edukasi tentang gerakan masyarakat sadar pangan.
\end{abstract}

Kata kunci : Siklamat, Minuman Jajajan

\begin{abstract}
Cyclamate is an artificial sweetener that is chemically processed. Cyclamate should not be used on food products for infants, toddlers, pregnant women and nursing mothers. The maximum limit for using cyclamate is $0-11 \mathrm{mg} / \mathrm{kg}$ body weight. The objective of this research was to determine cyclamate levels in school snack beverages in Palu City. This research used an observation method at eight locations in Palu City which was held on August 8-24, 2018. The analysis of cyclamate levels was carried out at the Food and Drug Supervisory Center in Palu. Twenty samples of snacks were obtained by accidental sampling. The analysis method was carried out by high performance liquid chromatography (HPLC). The results showed that the cyclamate level in school snack drinks in Palu City that exceeded the threshold perka BPOM $<350 \mathrm{mg} / \mathrm{Kg}$ was $35 \%$ with a level of 514.63 to $2963.43 \mathrm{mg} / \mathrm{Kg}$. For further research, it is recommended to examine more about the knowledge, attitudes and behavior of beverage vendors in locations that exceed the threshold perka BPOM <350 $\mathrm{mg} / \mathrm{Kg}$ as well as education about the movement of aware food community.
\end{abstract}

Keywords: Cyclamate, Snack Beverage. 


\section{PENDAHULUAN}

Secara umum produsen menggunakan Bahan Tambahan Pangan yang meliputi pewarna, pengawet, antioksidan, pemantap dan pemanis. Pemanis sintetis ini menimbulkan rasa manis serta dapat membantu mempertajam penerimaan terhadap rasa manis tersebut, tetapi kalori yang dihasilkan lebih rendah daripada gula murni. Pemanis sintetis yang banyak beredar dan dijual di masyarakat luas adalah siklamat ${ }^{(1)}$.

Siklamat adalah pemanis buatan yang diproses secara kimiawi. siklamat tidak boleh digunakan pada hasil pangan yang diperuntukkan bagi bayi, anak usia di bawah tiga tahun, ibu hamil dan ibu menyusui. Batas maksimum penggunaan Siklamat adalah 0-11 $\mathrm{mg} / \mathrm{kg}$ berat badan. Minuman berbasis air berperisa, termasuk minuman olahraga atau elektrolik dan minuman berpartikel tidak boleh melebihi $350 \mathrm{mg} / \mathrm{kg}$ sebagai asam siklamat yang dihitung terhadap produk siap konsumsi ${ }^{(2)}$.

Metode Analisis Kualitatif Siklamat menggunakan metode Gravimetri( ${ }^{(3)}$ (1) atau metode Pengendapan (SNI 01-2893-1992) ${ }^{(4)}$ sedangkan Analisis Kuantitatif menggunakan metode Kurva Kalibrasi Spektrofotometri $\mathrm{UV}^{(5)}$ metode HPLC pada panjang gelombang pengukuran $200 \mathrm{~nm}^{(6)}$ pengukuran $220 \mathrm{~nm}^{(7)}$ HPLC pada panjang gelombang $310 \mathrm{~nm}{ }^{(8)}$

Penelitian di Semarang menunjukkan sampel Es Lilin yang diperiksa mengandung 68,0\% natrium siklamat. Dari jumlah tersebut terdapat 3 sampel $(17,65 \%)$ yang melebihi batas maksimal ${ }^{(3)}$. Penelitian lain di Palangkaraya menunjukkan 5 sampel dari 12 sampel terdeteksi mengandung siklamat ${ }^{(4)}$. Hasil penelitian di Sekolah Dasar Lariangbangi Makassar menunjukkan bahwa 6 sampel yang diuji dua diantaranya mengandung pemanis sintetis siklamat dengan kadar 543,123 mg/kg dan $181,04 \mathrm{mg} / \mathrm{kg}^{(9)}$ Hasil Penelitian di Sekolah Dasar Wua-Wua Kendari pada 8 produk sirup jajanan semuanya mengandung siklamat dengan kadar 78-333 mg/ $\mathrm{kg}^{(10)}$ Hasil penelitian di Kota Banjarbaru menunjukkan $89 \%$ sampel juga tidak memenuhi syarat ${ }^{(1)}$.

Observasi pengamatan yang dilakukan oleh peneliti terhadap pedagang minuman di Kota Palu menyatakan bahwa siklamat biasa disebut juga sarimanis. mereka lebih sering memakai pemanis sintetis oleh sebab harganya lebih murah dan memberikan rasa manis lebih tinggi dibandingkan gula pasir putih.

Menurut Thamrin, konsumsi siklamat dalam dosis yang lebih akan mengakibatkan kanker kandung kemih. Selain itu juga dapat menyebabkan tumor hati, limfa dan paru ${ }^{(9)}$.

Pemanis sintesis atau rendah kalori umumnya digunakan di seluruh dunia dalam industri makanan, sering kali dikombinasikan untuk membatasi selera yang tidak diinginkan. Daftar pemanis yang diperbolehkan bervariasi antar negara. Badan POM telah menetapkan kadar $<350 \quad \mathrm{mg} / \mathrm{Kg}$ untuk penggunaan siklamat. Penting untuk memantau produk yang sangat dikonsumsi ini untuk memastikan kepatuhan dengan peraturan yang telah ditetapkan $^{(11)}$. 
Belum adanya publikasi tentang kadar Siklamat pada minuman jajanan di Kota Palu mendorong peneliti untuk melakukan penelitian. Penelitian dilakukan dengan tujuan untuk mengetahui Kadar Siklamat Pada Minuman Jajanan Sekolah di Kota Palu.

\section{METODE PENELITIAN}

Penelitian ini menggunakan metode observasi untuk memperoleh sampel minuman di 8 (delapan) lokasi di Kota Palu pada tanggal 8-24 Agustus 2018. Kegiatan analisis kadar Siklamat pada Balai Pengawas Obat dan Makanan di Palu. Sampel sebanyak 20 minuman jajajan diperoleh dengan cara accidental sampling. Metode analisis siklamat dengan cara KCKT.

Prinsip Kadar siklamat ditetapkan secara KCKT menggunakan detektor UV pada gelombang panjang $314 \mathrm{~nm}$, kemudian diderivatisasi menjadi N-dikloro sikloheksilamin dengan memakai natrium hipoklorit dalam suasana asam. Bahan/Baku Pembanding Natrium Siklamat BPFI, Pereaksi Larutan $\mathrm{H}_{2} \mathrm{SO}_{4} 6 \mathrm{~N}$ kedalam gelas kimia berisi $200 \mathrm{ml}$ aquades, kemudian ditambah $40 \mathrm{ml}$ H2SO4 kadar pekat 95-97\%. Aduk hingga menjadi merata. Larutan $\mathrm{NaHCO} 31 \%$ ditimbang 10 gram natrium bikarbonat, dimasukkan ke dalam gelas bertutup $1 \mathrm{~L}$, lalu tambahkan aquades hingga tanda lalu dikocok hingga larut. Larutan $\mathrm{NaClO}>3 \%$ Metanol Sikloheksan. Peralatan KCKT dilengkapi dengan detektor UV-Vis; corong pisah $250 \mathrm{ml}$; labu tentukur $100 \mathrm{ml}, 1 \mathrm{~L}$; gelas ukur bertutup $100 \mathrm{ml}, 250 \mathrm{ml}$; pipet volumetrik berukuran 2 $\mathrm{ml}, 5 \mathrm{ml}, 10 \mathrm{ml}, 25 \mathrm{ml}$; neraca analitik serta peralatan lainnya.

Cara Penetapan; Larutan A, B, C disuntikkan dengan terpisah kedalam alat KCKT, kondisi didesain sebagai berikut:

(a) Fase gerak: Metanol : air derajat KCKT (90:10). Gunakan Kolom C18 (25 cm x 4,6 $\mathrm{mm}$ ), berukuran $5 \mu \mathrm{m}$.

(b) Detektor UV pada gelombang panjang 314 $\mathrm{nm}$, Laju alir 1,2 ml/menit dengan volume penyuntikan $20 \mu \mathrm{l}$.

(c) Interpretasi Hasil Kadar siklamat $(\mu \mathrm{g} / \mathrm{g}$ atau $\mathrm{mg} / \mathrm{kg}$ ) dalam sampel dihitung menggunakan rumus sebagai berikut: Kadar Siklamat $=\frac{\operatorname{Csp} \times F}{w}$

Csp $=$ Kadar siklamat diperoleh dari perhitungan kurva kalibrasi $(\mu \mathrm{g} / \mathrm{ml})$

$\mathrm{F} \quad=$ Faktor pengenceran $(\mathrm{ml})$

$\mathrm{W}=$ Bobot $(\mathrm{g})$

Persyaratan batas maksimum siklamat dalam minumkan ringan $350 \mathrm{mg} / \mathrm{kg}$ (Perka BPOM No 4 tahun 2014) (MA PPOMN 67/PA/11). Penelitian ini telah memiliki persetujuan etik ethical Approval dari Komisi Etik Poltekkes Kemenkes Palu Nomor LB. 01.01.KE/01/173./IX/2018.

\section{HASIL}

Selama 18 hari penelitian, baik pada pengumpulan sampel hingga analisis di Balai POM Palu menunjukkan bahwa dari 20 sampel pemeriksaan terdapat 7 sampel yang tidak memenuhi syarat BPOM $<350 \mathrm{mg} / \mathrm{Kg}$ atau $35 \%$ sampel minuman tidak memenuhi syarat ambang maksimun siklamat dalam minuman. 
Tabel 1. Analisis kadar siklamat pada minuman jajanan Sekolah di Kota Palu tahun 2018

\begin{tabular}{ccc}
\hline Kode & Kadar & Interpretasi Hasil \\
Sampel & Siklamat & \\
\hline 1 & 172,98 & Memenuhi Syarat \\
2 & 118,24 & Memenuhi Syarat \\
3 & 212,41 & Memenuhi Syarat \\
4 & 674,41 & Tidak Memenuhi Syarat \\
5 & 543,20 & Tidak Memenuhi Syarat \\
6 & 1084,36 & Tidak Memenuhi Syarat \\
7 & 58,24 & Memenuhi Syarat \\
8 & 143,72 & Memenuhi Syarat \\
9 & 103,24 & Memenuhi Syarat \\
10 & 212,41 & Memenuhi Syarat \\
11 & 586,87 & Tidak Memenuhi Syarat \\
12 & 2963,43 & Tidak Memenuhi Syarat \\
13 & 215,24 & Memenuhi Syarat \\
14 & 143,41 & Memenuhi Syarat \\
15 & 674,41 & Tidak Memenuhi Syarat \\
16 & 514,63 & Tidak Memenuhi Syarat \\
17 & 112,41 & Memenuhi Syarat \\
18 & Dibawah & Memenuhi Syarat \\
& batas & \\
19 & deteksi & \\
20 & 112,93 & Memenuhi Syarat \\
\hline
\end{tabular}

Sumber : Data Primer, 2018

\section{PEMBAHASAN}

Pemanis sintesis umumnya digunakan dalam makanan sebagai alternatif gula untuk memberikan rasa manis dengan sedikit atau tanpa kalori. Bahan tambahan makanan yang ditambahkan ke makanan untuk menyebabkan efek teknis seperti pemanis. Pemanis dikelompokkan menjadi dua kategori utama, pemanis curah dan intens. Pemanis massal, seperti gula alkohol, memberikan efek tekstur dan pengawet untuk makanan rendah kalori, dengan kekuatan pemanis setara atau kurang relatif terhadap sukrosa. Alkohol gula telah diberikan kuantum satis, yang berarti bahwa mereka tidak cukup berbahaya untuk tidak memiliki batasan kuantitas tertentu. Pemanis intens memiliki tingkat pemanis yang lebih besar daripada sukrosa dengan berbagai potensi. Senyawa ini dapat berupa sintetis, semi-sintetik atau alami. Mayoritas adalah senyawa sintetis termasuk aspartam (ASP), sukralosa (SCL), sakarin (SAC), siklamat (CYC), asesulfamepotassium (ACS-K), alitame (ALI), neotame (NEO) dan dulcin (DUL). Neohesperidine dihydrochalcone (NHDC) adalah pemanis semi-sintetik, sedangkan stevioside (STV) dan rebaudioside (REB) A adalah pemanis alami ${ }^{(11)}$.

Daftar pemanis yang diperbolehkan bervariasi di antara negara-negara di seluruh dunia. Misalnya, CYC dan NHDC tidak disetujui untuk digunakan sebagai aditif makanan oleh Food and Drug Administration AS tetapi diotorisasi di Uni Eropa (UE). Pemanis tertua di pasaran, SAC disetujui untuk digunakan di hampir 90 negara. Ini memiliki kekuatan pemanis sekitar 450 kali dari sukrosa dan menunjukkan kelarutan air yang tinggi dan stabilitas penyimpanan. Pada 1980-an, konsumsinya dikaitkan dengan kanker kandung kemih pada tikus dan karenanya dilarang di Kanada. Meskipun terasa pahit setelah dimakan, namun disetujui untuk digunakan di banyak makanan dan minuman. Tidak seperti SAC, DUL tidak memiliki rasa pahit setelah dikonsumsi dan memiliki kapasitas pemanis sekitar 250 kali dari sukrosa. Namun, DUL belum mendapatkan penggunaan luas karena kekhawatiran akan toksisitasnya. Tidak disetujui untuk digunakan di AS. Ditemukan pada tahun 1967, ACS-K 
menunjukkan stabilitas penyimpanan yang baik memiliki 200 kali lebih manis daripada sukrosa dan penggunaannya dikaitkan dengan rasa pahit setelah dimakan pada konsentrasi tinggi. ACS-K secara luas digunakan dan disetujui di 90 negara dengan beberapa masalah kesehatan terkait dengan penggunaannya, memiliki kelarutan dengan air yang sangat baik dan stabil pada saat memasak dan memanggang suhu ${ }^{(11)}$.

Sebaliknya, ASP adalah pemanis artifisial yang paling kontroversial mengenai efek kesehatannya. Ada laporan tentang efek neurologis yang merugikan dan kanker pada tikus. Memiliki rasa 180 kali lebih manis daripada sukrosa dan dengan demikian hanya jumlah kecil ditambahkan ke makanan untuk mencapai rasa manis yang diinginkan. Karena ASP tidak stabil terhadap panas, ia terdegradasi dalam cairan selama penyimpanan berkepanjangan. Karena itu, tidak dapat digunakan dalam memanggang atau memasak dan produk minuman. Fenilalanin adalah metabolit ASP, yang tidak dapat dimetabolisme oleh orang-orang dengan fenilketonuria, kelainan genetik yang langka. Asupan fenilalanin yang berlebihan telah dikaitkan kerusakan otak. Akibatnya, semua produk yang mengandung ASP harus diberi label untuk menunjukkan adanya sumber fenilalanin $^{(11)}$.

Contoh klasik adalah perpaduan sakarin Siklamat yang diformulasikan dalam rasio 1:10. rasa pahit setelah menkomsumsi sakarin ditutupi oleh Siklamat dan karena efek aditif kekuatan pemanis dari campuran lebih besar. Produk makanan yang mengandung pemanis sangat dipromosikan sebagai bermanfaat untuk pengobatan obesitas dan manajemen diabetes. Pemanis dapat ditemukan dalam sejumlah besar produk makanan termasuk yang berikut ini: pemanis meja, minuman berkarbonasi dan non-karbonasi, makanan yang dipanggang, pengawet dan permen, minuman beralkohol, permen, dan produk susu seperti yogurt dan es krim. Ada banyak kontroversi seputar efek kesehatan yang merugikan dari pemanis nongizi. Konsumen di seluruh dunia telah melaporkan efek samping yang terkait dengan konsumsi pemanis, termasuk perubahan suasana hati dan perilaku, iritasi kulit, sakit kepala, alergi, kesulitan pernapasan, dan kanker. Karena itu, penting untuk memantau dan mengontrol konsentrasi pemberi makan dalam makanan untuk memastikan kepatuhan dengan peraturan spesifik negara yang berbeda.

Badan POM membatasi jumlah pemanis yang ditambahkan ke makanan dan menetapkan dosis maksimum yang dapat digunakan untuk komoditas makanan tertentu. Untuk memastikan bahwa produk mematuhi peraturan, perlu memiliki metode yang andal, kuat, dan kuantitatif untuk penentuan simultan beberapa pemanis yang biasa digunakan dalam satu analisis. Selain analisis multi-pemanis, ada juga kebutuhan untuk metode analitik pemanis tunggal seperti dalam kasus Siklamat.

Pemanis Siklamat sendiri ditemukan pada 1930-an. Memiliki rasa 30-40 kali lebih manis 
daripada sukrosa dengan efektivitasnya meningkat bila digunakan dalam kombinasi dengan pemanis lainnya. Ini banyak digunakan sebagai agen pemanis di berbagai makanan dan minuman rendah kalori di banyak negara. Namun, Siklamat dilarang untuk penggunaan komersial sebagai aditif makanan oleh US FDA karena temuan penelitian yang menghubungkan konsumsinya dengan kanker kandung kemih pada tikus. Di bawah larangan itu, Siklamat tidak bisa ditambahkan atau terdeteksi dalam makanan. Karena ada peningkatan jumlah makanan yang dijual di AS yang diimpor dari negara lain, di mana Siklamat disetujui untuk digunakan sebagai aditif makanan, penting untuk memilikinya metodologi analitik untuk deteksi dan konfirmasi Siklamat di dalam minuman dan makanan yang beredar.

Metode analitik terkini untuk konfirmasi dan kuantifikasi pemanis harus memungkinkan konfirmasi identitas analit agar kompatibel dengan standar saat ini. Berbagai metode untuk penentuan pemanis sintetik telah dilaporkan. Metode yang paling umum menggunakan kromatografi cair kinerja tinggi (KCKT) dengan berbagai jenis deteksi. Teknik ini memungkinkan pemanis tunggal dan banyak analit. sementara penentuan menyediakan analisis kuantitatif dan kepercayaan. Meskipun KCKT adalah teknik yang menarik dengan daya penyelesaian sebanding yang tersedia dengan biaya lebih rendah dengan konsumsi pelarut yang lebih sedikit, namun KCKT kurang populer karena ketahanan yang terbatas. Karena ketersediaan KCKT meningkat di laboratorium, akan ada peningkatan kebutuhan untuk lebih banyak metode menggunakan prosedur ini. Ini akan memungkinkan analisis tinggi makanan dan minuman untuk pemanis menggunakan pemisahan kromatografi cepat. Di masa depan, ada banyak metode untuk mengembangkan instrumentasi dan opsi persiapan sampel mengingat bahaya penggunaan siklamat yang berlebihan.

Hasil penelitian menunjukkan bahwa dari 20 pemeriksaan terdapat 7 sampel yang tidak memenuhi syarat perka BPOM < $350 \mathrm{mg} / \mathrm{Kg}$ atau $35 \%$ minuman yang menjadi sampel tidak memenuhi syarat ambang maksimun siklamat dalam minuman.

Siklamat adalah pemanis buatan yang diproses secara kimiawi dan senyawa tersebut tidak terdapat di alam. siklamat dilarang digunakan pada produk pangan yang diperuntukkan bagi bayi, anak usia di bawah tiga tahun, ibu hamil dan/atau ibu menyusui. Batas maksimum penggunaan Siklamat adalah 0-11 $\mathrm{mg} / \mathrm{kg}$ berat badan. Minuman berbasis air berperisa, termasuk minuman olahraga atau elektrolik dan minuman berpartikel tidak melebihi $350 \mathrm{mg} / \mathrm{kg}$ sebagai asam siklamat dihitung terhadap produk siap konsumsi ${ }^{(2)}$.

Penelitian di Semarang menunjukkan bahwa $68,0 \%$ es lilin yang diperiksa mengandung natrium siklamat ${ }^{(3)}$. Penelitian di Kota Palangka Raya menunjukkan terdapat 5 sampel dari 12 sampel yang diperiksa terdeteksi mengandung siklamat ${ }^{(4)}$. 
Hasil penelitian di Sekolah dasar Lariangbangi Makassar menunjukkan bahwa 6 sampel yang diuji dua diantaranya mengandung pemanis sintetis siklamat dengan kadar $543,123 \mathrm{mg} / \mathrm{kg}$ dan $181,04 \mathrm{mg} / \mathrm{kg}^{(9)}$ Hasil Penelitian di Sekolah Dasar Wua-Wua Kendari pada 8 produk sirup jajanan semuanya mengandung siklamat dengan kadar 78-333 mg/kg (10) Hasil penelitian di Kota Banjarbaru menunjukkan 9 sampel dari 11 sampel es krim mengandung siklamat dengan kadar tertinggi $7,37 \mathrm{~g} / \mathrm{kg}^{(1)}$.

Dalam rilis BPOM pada laman http://klubpompi.pom.go.id/id/tanyajawab/item/238-berapakah-batas-maksimumpenggunaan-siklamat-dan-sakarin menyatakan bahwa berapakah batas maksimum penggunaan siklamat dan sakarin, tergantung jenis produknya (lihat permenkes 722/1988 tentang Bahan Tambahan Makanan), dibawah ini beberapa contoh penggunaan siklamat dengan batas maksimum $500 \mathrm{mg} / \mathrm{kg}$ bahan, sedangkan sakarin 50-300 mg/kg bahan.

Hasil penelitian Purwaningsih dkk, menyatakan bahwa terdapat hubungan antara pengetahuan pembuat es lilin dengan kadar natrium siklamat dalam es lilin yang dibuatnya $(\mathrm{p}=0,00)$, dan ada hubungan yang nyata antara sikap produsen es lilin dengan kadar natrium siklamat dalam es lilin yang diproduksinya $(\mathrm{p}=0,00)$. Olehnya itu perlu dilakukan edukasi lebih lanjut tentang gerakan masyarakat Sadar Pangan dalam hal ini kepada penjaja minuman dilokasi yang melebihi ambang batas perka $\mathrm{BPOM}<350 \mathrm{mg} / \mathrm{Kg}$.

\section{KESIMPULAN DAN SARAN}

Kadar Siklamat pada minuman jajanan sekolah di Kota Palu yang melebihi ambang batas perka BPOM < $350 \mathrm{mg} / \mathrm{Kg}$ sebanyak 35\% dengan kadar 514,63 hingga 2963,43 $\mathrm{mg} / \mathrm{Kg}$. Disarankan agar penelitan lebih lanjut tentang meneliti tentang pengetahuan, sikap dan perilaku penjaja minuman dilokasi yang melebihi ambang batas perka BPOM <350 $\mathrm{mg} / \mathrm{Kg}$. Disamping itu memberikan edukasi tentang gerakan masyarakat sadar pangan.

\section{DAFTAR PUSTAKA}

1. Nurlailah, Alma NA, Oktiyani N. Analisis kadar siklamat pada es krim di kota Banjarbaru. Med Lab Technol J. 2017;3(1):77-81.

2. BPOM. Peraturan Kepala Badan Pengawas Obat Dan Makanan Republik Indonesia Nomor 4 tahun 2014 tentang batas maksimum penggunaan bahan tambahan pangan pemanis [Internet]. Perka BPOM Nomor 4 Tahun 2014 Jakarta, Indonesia: BPOM; 2014 p. 1-63. Available from: jdih.pom.go.id/showpdf.php?u=810

3. Purwaningsih R, Astuti R, Salawati T. Penggunaan natrium siklamat pada es lilin berdasarkan di Kelurahan Srondol Wetan Dan Pedalangan Kota Semarang. Pangan dan Gizi. 2010;01(02):19-26.

4. Hartono R. Identifikasi Siklamat Pada Minuman Jajanan Di Kawasan Pendidikan Kota Palangka Raya. Fak Ilmu Kesehat Univ Muhammadiyah Palangka Raya. 2014;35.

5. Hadju N a, Tuju ITDJ, Ludong IMM, Langi ITM. Analisis Zat Pemanis Buatan Pada Minuman Jajanan Yang Dijual Di Pasar Tradisional Kota Manado. J Teknol Pertan. 2012;

6. Wibowotomo B. Pengembangan metode penetapan kadar siklamat berbasis kromatografi cair kinerja tinggi guna diimplementasikan dalam kajian paparan. Teknol dan Kejuru. 2010;33(1):81-92.

7. Widyaningsih R, Utami PI. Analisis Siklamat pada Agar-agar yang beredar di pasar Wage Purwokerto dengan Metode Kromatografi Cair KInerja Tinggi. Pharmacy [Internet]. 2009;06(03):65-72. 
Available

from:

http://jurnalnasional.ump.ac.id/index.php/P

HARMACY/article/view/433

8. Li J, Liu Y, Liu Q, Hui J, Liu Y. Oncartridge derivatisation using matrix solid phase dispersion for the determination of cyclamate in foods. Anal Chim Acta. 2017;972:46-53.

9. Zulfikar Thamrin, Sirajuddin Saifuddin, Zakaria. Analisis zat pemanis buatan (sakarin dan siklamat) pada pangan jajanan di SD Kompleks Lariangbangi Kota Makassar [Internet]. Universitas Hasanuddin; 2014. Available from: repository.unhas.ac.id/handle/123456789/1 1379

10. Setiawan EA, Ibrahim MN, Wahab D, Nuh Ibrahim M, Wahab D. Analisis kandungan zat pemanis sakarin dan siklamat pada minuman yang di perdagangkan di Sekolah Dasar di Kelurahan Wua-Wua Kota Kendari. Sains dan Teknol Pangan. 2016;1(1):45-9.

11. Shah R, Jager LS De. Recent Analytical Methods for the Analysis of Sweeteners in Food: A Regulatory Perspective. Food and Drug Administration Papers. 5 [Internet]. Nebraska City; 2017. Available from: http://digitalcommons.unl.edu/cgi/viewcont ent.cgi article $=1013 \&$ context $=u$ sfda 